\title{
La utilización de menores en campañas de comunicación solidaria. El caso de Manos Unidas.
}

\section{The use of children in solidarity communication campaigns. The case of Manos Unidas}

\author{
Montse Vázquez Gestal*, Sandra Ortega Bastida**, Ana Belén Fernández Souto*** \\ *Profesora Titular, Universidad de Vigo, España. \\ **Graduada en Publicidad y Relaciones Públicas, Universidad de Vigo, España. \\ *** Profesora Titular, Universidad de Vigo, España.
}

Resumen

\begin{abstract}
La comunicación de las ONGs se desarrolla con el objetivo de visibilizar las carencias en determinadas poblaciones con la intención de encontrar alternativas o soluciones eficientes a ellas. Hablamos de un canal de transmisión para que los individuos puedan llegar a conocer cómo viven, o sobreviven, las personas que habitan los países en desarrollo. Este tipo de comunicación utiliza como reclamo en muchas ocasiones a los menores, ya sea para informar o para persuadir dependiendo de las campañas. En este artículo, analizamos la labor de la ONG Manos Unidas a través de los spots que ha desarrollado para dar a conocer sus actividades, con el objetivo de analizar la presencia de menores en ellos y la labor que pretende desarrollar con ese tipo de imágenes.
\end{abstract}

Palabras clave: comunicación solidaria, ONGs, menores, sensibilización.

Abstract

The communication of NGO's is aimed at highlighting the deficiencies in specific populations, with the goal of finding efficient alternatives or solutions. This is a transmission channel used to help individuals understand how the inhabitants of developing countries live, or survive. These communications ofter use children as a a trigger, either to inform or to persuade, depending on the campaigns. In this article, we analyze the work of the NGO Manos Unidas through the advertising spots they have produced to promote their activities, with the objective of analyzing the presence of children and the goals that the organization intends to reach by using this kind of images.

Keywords: solidarity communication, NGO's, children, awareness.

\section{Introducción}

La ONU (2016) define las ONGs como una "agrupación de ciudadanos voluntarios, sin ánimo de lucro, que se organizan en un nivel local, nacional o internacional para abordar cuestiones de bienestar público (...), con una labor concreta y formadas por gente que comparte un mismo interés". Ese interés común es el que les lleva a utilizar la comunicación con el objetivo de visibilizar las carencias en determinadas poblaciones y encontrar alternativas o soluciones eficientes a ellas. Un tipo de comunicación que, en ocasiones, utiliza como reclamo a menores, ya sea para informar o para persuadir dependiendo de las campañas y que, normalmente, se incluye dentro de la denominada publicidad social.

Copyright (C) 2018 (Montse Vázquez Gestal, Sandra Ortega Bastida, Ana Belén Fernández Souto). Licensed under the Creative Commons Attribution-NonCommercial Generic (cc by-nc). Available at http://obs.obercom.pt. 
En este entorno, desarrollamos este pequeño estudio centrado en la comunicación de una de las ONGs de mayor relevancia en España, Manos Unidas, intentando analizar una parte de su publicidad social y centrándonos, simplemente, en la presencia que en ella tienen los menores para intentar conseguir ese apoyo y sensibilización que le permita desarrollar sus proyectos. Desde el punto de vista del análisis de piezas publicitarias, la comunicación de Manos Unidas se sitúa en el campo de la sensibilización y de la recaudación de fondos, ahondando en un elemento más, la presencia de los menores, cuyo uso como reclamo publicitario, tan presente en la comunicación comercial, se expande a otros ámbitos como es el caso de la comunicación solidaria. La Asociación de Usuarios de la Comunicación destaca en su informe Menores y Medios de Comunicación, Publicidad, Televisión e Internet que, aproximadamente, un tercio de los anuncios televisivos están protagonizados por uno o varios menores, independientemente del público al que vaya destinado, dotando al producto o servicio de un valor añadido, puesto que cualquier niño tiene la capacidad de transmitir dulzura, inocencia, ingenuidad y debilidad. Son aquella parte de la sociedad que necesita más protección y ello se refleja también en las acciones de la ONGs.

Al hablar de la comunicación en las organizaciones como Manos Unidas, Elísa Nos (2003) destaca dos papeles diferentes: los niños como protagonistas con apariencia de felicidad y que están sonriendo, para señalar avances en la ayuda y, al contrario, con miradas tristes y en situación de desamparo cuando se trata de captar fondos, aumentar los apadrinamientos o solicitar la ayuda de los espectadores. En nuestro caso pretendemos corroborar si eso ocurre en las piezas analizadas, es decir, si las imágenes son más dramáticas cuando se trata de pedir ayuda y más positivas cuando se busca destacar los logros obtenidos y si la percepción del público también es esa.

\section{El nacimiento de las ong}

Teniendo como referencia la definición de ONG que nos facilita la ONU, mencionada en el inicio, añadimos algunos datos para su caracterización, habida cuenta de la diversidad de tipos, causas y herramientas en el desarrollo de sus trabajos. Picas (2001) destaca que hablamos de entidades que buscan cumplir una misión, lo que les diferencia de las entidades lucrativas, ya que las ONG desarrollan una estrategia acorde a la misión con la que trabajar, en este caso siempre vinculada a una causa, y que ésta ayude a diferenciar y delimitar cuáles son los objetivos que persiguen.

Hildegart (2006) recuerda además que es muy complicado saber cuál es el punto exacto en el que nacen estas organizaciones, aunque son muchos investigadores los que señalan como fecha de su nacimiento el 27 de febrero de 1950, pues de ese día es el primer documento oficial de las Naciones Unidas donde se hace referencia y se define el término Organización No Gubernamental. Dicho autor destaca tres rasgos para definir dichas entidades:

No gubernamentales, es decir, que no se han creado ni forman parte del Gobierno, ni dependen de él. Sin embargo, son muchas las que en la actualidad están pidiendo ayuda a los estados para poder ejercer su labor, cuestión criticada por aquellos que consideran que esta forma de financiación hace que, en cierta medida, se vean condicionadas. 
- Realizan su labor sin ánimo de lucro, es decir, simplemente lo realizan para ayudar a terceras personas que lo necesitan. No se encuentra dentro de su ética o moral recibir dinero a cambio de realizar su trabajo, sino que realizan labores de conseguir dinero para, mediante diferentes procedimientos, ayudar a los distintos países globalmente o a personas individualmente, que no cuentan con los recursos suficientes.

- Realizan una actividad social. Su objeto principal es la ayuda y cooperación junto con distintas organizaciones o asociaciones para mejorar la situación de terceras personas. Están formadas por voluntarios y socios que aportan donaciones para poder realizar las actividades propuestas. Casi todas las ONG se especializan en uno o varios temas relacionados, de este modo pueden acercarse más al problema y solucionarlo.

En el caso de España, este tipo de entidades llegaron con cierto retraso (Gómez, 2005). La Guerra Civil española y la dictadura franquista ralentizan la situación política y social del país; hasta el año 1977, España sigue recibiendo préstamos del Centro de Desarrollo Tecnológico e Industria, por lo que no es hasta después de esa fecha que pasa a convertirse en país emisor de ayuda y no a la inversa. Hasta ese momento en nuestro país actuaban Cáritas (1941) e Intermón (1956). Es a partir de la década de los 80 cuando aparecen un elevado número de ONGs, lo que deriva de aparición de ayudas periódicas a la creación de las mismas, una de las más importantes la constituye el sistema de subvenciones implantado por el Ministerio de Asuntos Exteriores español en el año 1984 para fomentar actividades de desarrollo.

En 1985, España se integra en la Unión Europea lo que beneficia a este tipo de organizaciones que pueden acceder a sus recursos. En 1992, se funda el European Community Humanitarian Office, cuyo objetivo principal es el salvar y preservar la vida del ser humano. Gracias a las sugerencias y recomendaciones de los altos cargos de esta entidad, solo dos años más tarde de su fundación, las ONG españolas ya eran capaces de percibir aproximadamente el $10 \%$ del presupuesto total lo que demuestra la capacidad de progreso de las entidades españolas en la captación de fondos.

En 1986 nace CONGDE (Coordinadora de ONGs para el Desarrollo de España) de la mano de Ayuda en Acción, IEPALA (Instituto de Estudios Políticos para América Latina y Africa) y Medicus Mundi. Dicha coordinadora busca convertirse en una plataforma de interacción entre aquellas organizaciones de carácter social que tienen como labor y misión la cooperación internacional, educar en pro del desarrollo y/o realizar acciones de ayuda humanitaria.

El Código de conducta elaborado por la CONGDE (2008) añade que estas organizaciones deben contar con una estructura organizada y registrada para contar con una base jurídica y legal; su finalidad debe ser únicamente de solidaridad y cooperación nacional e internacional, deben responder a situaciones de emergencia y garantizar la ayuda a todo individuo o causa que la necesite; debe tener el apoyo de la sociedad en el desarrollo de sus prácticas y recibir colaboración por parte de ésta; es necesario que cuente con los recursos económicos suficientes para hacer frente a cualquier emergencia o causa, al igual que personal indicado que lleve a cabo el trabajo en cada una de las situaciones; tanto la política como los mecanismos que utilizan deben contar con la total transparencia, por lo tanto todo documento que sea relevante tiene la obligación de quedar expuesto al uso público. 


\section{La comunicación de las ONG}

El uso de la comunicación en el trabajo de este tipo de entidades es relevante e importante, ya que nace de la necesidad de transmitir las carencias de cierta parte de la población para buscar soluciones a los problemas y alternativas eficientes. Es decir, si no existiera este tipo de comunicación muchos de los individuos que se encuentran en una posición más beneficiosa no llegarían a enterarse de cómo viven, o sobreviven, las personas que habitan los países en desarrollo.

Las organizaciones no gubernamentales tienen la ardua necesidad de realizar acciones de comunicación con el único fin de llegar al público, transmitirles el mensaje adecuado a la actividad o función que van a desarrollar y recibir a cambio la ayuda de estas personas. Es importante que las ONG, para conseguir posicionarse en el Top Mind de los individuos, deban darse a conocer por medio de la comunicación, tanto la organización como estructura como el trabajo que realizan. Al igual que ocurre en el ámbito más comercial, la gran cantidad de entidades de cooperación que existen en la actualidad, obligan a buscar una diferenciación, habida cuenta que las mejor posicionadas en la mente de los individuos son aquellas que llevan más años trabajando o las que realizan la comunicación más atrayente. Al igual que los productos en el mercado deben tener claras sus acciones y ámbitos de actuación para que las personas identifiquen y decidan en qué causas quieren colaborar.

La comunicación de las ONG suele estar construida sobre trágicos testimonios e imágenes desoladoras recreando el entorno en el que se desarrollan sus principales actividades y cooperando con otras asociaciones u organizaciones, intentando llegar al corazón de los espectadores, buscando una respuesta más emocional y beneficiarse de dichas reacciones, hacerle abrir los ojos frente a una situación trágica y adversa.

Las ONG utilizan lo que se conoce como publicidad social, que presenta diferencias con la comunicación comercial, con una finalidad económica y centrada en la venta de un producto y/o servicio pero, también mantienen algunos elementos en común, ambas comparten el mismo tipo de público, quieren hacerle llegar un mensaje con una intención determinada y usan los mismos medios y soportes, entre otros. En el caso de la comunicación comercial la intención es vender productos o servicios, dar a conocer una novedad del mercado, crear imagen de marca.... Por el otro lado, la publicidad social busca provocar un cambio en el comportamiento o la actitud de la sociedad con la única finalidad de mejorarla.

Alvarado (2005) define este tipo de publicidad social como aquella "actividad comunicativa de carácter persuasivo, pagada, intencional e interesada que sirve, a través de los medios publicitarios, a causas concretas de interés social", si bien aclara esta autora el concepto de 'pagada', ya que en muchos casos este tipo de comunicación es desarrollada por agencias y medios de manera altruista y sin recibir una contraprestación por el servicio prestado.

Esta publicidad tiene por objeto dar a conocer causas sociales y buscar la colaboración del público a través de sus mensajes. Causas que afectan a una parte importante de la población, bien por una situación puntual, caso de las catástrofes naturales, bien por problemas que tiene un recorrido más dilatado en el tiempo, caso de la pobreza o la erradicación e investigación de enfermedades. Para Alvarado (2005) la publicidad social puede cumplir tres objetivos distintos: hacer una denuncia acerca de un problema o situación injusta buscando la crítica y el apoyo de la sociedad; sensibilizar a los individuos de un problema que alcanza una mayor importancia dentro de la sociedad y que busca la involucración de ésta, es decir, la necesidad de dar 
un paso más allá a su simple entendimiento. Y, por último, impulsar una acción que puede llevarse a cabo en un momento próximo o una acción a largo plazo.

Con respecto al tipo de comunicación que estas entidades desarrollan, Hildegart (2006) destaca cuatro formas diferentes:

- La comunicación en la educación para el desarrollo, cuya finalidad es educativa y suele limitarse casi exclusivamente a niños y adolescentes.

- La comunicación para la sensibilización, con un fuerte enfoque emotivo.

- La comunicación con el fin de captar fondos. Utilizan mensajes con una gran carga dramática, a veces con resultados contradictorios.

- La comunicación como herramienta de presión. Su medio principal es Internet para dar más fuerza y extensión a las campañas. Se caracteriza por la denuncia y el llamamiento a la movilización.

Añadimos un tipo más, aportado por Gumucio (2010: 37) y que denomina comunicación por el cambio social, "un proceso de diálogo y debate, basado en la tolerancia, el respeto, la equidad, la justicia social y la participación activa de todos". Se caracteriza por la importancia de los actores sociales por encima del producto, que actúan como un simple complemento. Además, está latente su preocupación por la cultura y todo lo que está conlleva.

"La participación democrática y la apropiación del proceso, [...] el proceso de comunicación no puede ignorar las particularidades de cada cultura y cada lengua, [...] es fundamental la generación de contenidos propios, que rescaten el saber acumulado a través de muchas generaciones, [...] el uso de la tecnología debe dimensionarse de acuerdo con las necesidades de cada proceso comunicacional, [...] la constitución de redes contribuye a consolidad los procesos, y el intercambio los enriquece." (p. 38)

En cuanto al uso de los medios de comunicación, instrumento indispensable para que las ONG puedan hacerse ver, llegar al máximo número de individuos y conseguir sus objetivos, cabe decir que no todas las causas son iguales ni requieren del mismo tipo de comunicación o material a utilizar. Aun así, la televisión es el medio por excelencia, aunque el precio por espacio publicitario es mayor, también recoge el mayor número de espectadores. En muchos casos, las ONGs reciben ayuda de estos medios de comunicación que realizan el trabajo sin recibir una compensación económica, si bien dicha colaboración les otorga la etiqueta de la 'solidaridad', de la participación en la sociedad y de colaborar es una causa responsable.

En todo caso, el desarrollo de los nuevos medios ha provocado también cambios en este tipo de instituciones desde el punto de vista de la comunicación, debido a la presencia cada vez más fuerte de las ONGs en Internet $y$, consecuentemente, en las redes sociales. Una inmensa mayoría cuenta con una página web o un blog donde redactan los trabajos realizados y cuentan con un espacio desde el que se puede realizar una donación o convertirse en socio/voluntario/colaborador.

La posibilidad de creación de comunidades a través de las redes sociales ha abierto muchas puertas tanto para empresas y marcas como para organizaciones, incluyendo en estas últimas a las ONGs. Son muchas las que cuentan con un perfil en las redes con mayor afluencia de público. Con Facebooky Twitterconsiguen generar una interacción más cercana con el público y pueden hacerles partícipes de las novedades de los proyectos llevados a cabo o últimas noticias de actualidad. Otra red social muy utilizada es YouTube, una plataforma que permite subir vídeos de manera gratuita y es una alternativa a la televisión para 
determinados segmentos de población, las ONGs pueden subir sus campañas en formato spot o con una duración mayor y si se sabe hacer un buen uso de ella en consonancia con las demás redes sociales, se puede llegar a un número elevado de espectadores.

\section{Caso Manos Unidas}

Manos Unidas nace en 1959 y se define como 'Asociación de la Iglesia Católica en España para la ayuda, promoción y desarrollo del Tercer Mundo. Es una ONG para el Desarrollo, de voluntarios, católica y seglar', cuya misión es erradicar el hambre en el mundo, tal y como aparece en su web.

La declaración de guerra al hambre hecha por FAO en 1955 hace que las mujeres de Acción Católica en España desarrollen en 1960 la primera campaña de lo que se conocería, posteriormente, como Manos Unidas. La gran sequía en la India lleva por primera vez a la televisión su Campaña contra el Hambre, obteniendo una recaudación de 22.961.268 pesetas (unos 138.000 de los actuales euros). En 1973 crean cinco áreas de proyectos prioritarios: educación, sanidad, promoción de la mujer, agricultura y ámbito social. En 1978, la Campaña contra el Hambre adquiere más protagonismo y comienza a conocérsele por su actual nombre, Manos Unidas Comité Católico de la Campaña contra el Hambre en el Mundo. En 2007 consigue la mayor recaudación de la historia de la organización, 62 millones de euros. En 1962 ve la luz el primer cartel de la organización y en 1980 aparece el primer anagrama, la bola del mundo con las manos, que forma parte del logotipo actual. En 1999 se crea la primera web y en 2012 aparece en redes sociales (YouTube, Facebook, Twitter e Instagram).

Fotografía 1: Primer cartel de la Campaña contra el Hambre

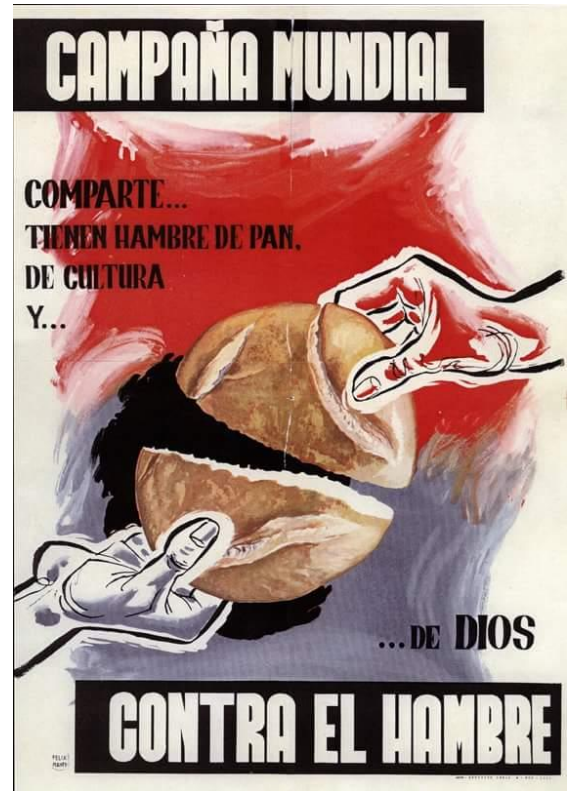

Su comunicación es muy completa, tanto en redes sociales como en material publicitario. Cuenta con una página web muy bien desarrollada en la que se puede encontrar toda la información necesaria acerca de la 
organización, cómo trabajan y cuáles son sus objetivos. Tiene una sección que permite al usuario hacerse socio y hacer un seguimiento más exhaustivo del trabajo que están realizando, o hacer una donación en un momento específico o para una causa concreta.

El sitio web se completa con una sección de sala de prensa que recoge todo el material necesario para los medios. Se pueden encontrar tanto imágenes de archivo, como los logotipos oficiales de la organización y los carteles de las campañas del año 2015; vídeos, aunque en este caso enlaza directamente con el canal oficial de YouTube en el que están disponible todo el material grabado, tanto spots como reportajes; audio, con todas las ruedas de prensa desde el año 2015 hasta la actualidad; dossiers de prensa, donde está disponible toda la documentación informativa, desde boletines, intervenciones, programas hasta informes. Por último, y no por ello menos relevante, disponen dentro de la sala de prensa de un apartado de material publicitario. En él se encuentran todas las propuestas para algunas de las campañas más recientes de Manos Unidas: banners, anuncios para prensa impresa, cuñas de radio, imágenes para cambiar la identidad de Facebook y Twitter, spots de televisión, recursos de inserción gratuita o página completa/media página. De esta manera los medios de comunicación disponen de estos materiales y la ONG no tiene la necesidad de pagar por comprar un espacio en los medios. El problema se plantea cuando el contenido no interesa pues entonces hay que pagar para colocar los recursos en los medios de comunicación.

En cuanto a redes sociales, Manos Unidas cuenta con perfiles en Facebook, Twitter, YouTube e Instagram. En ellos destaca el contenido propio, noticias de actualidad sobre proyectos, reportajes realizados por corresponsales voluntarios de la organización, peticiones para campañas específicas y pequeños proyectos llevados cabo por las circunstancias del momento. Todas ellas tienen una actividad muy dinámica, con publicaciones casi diarias como en el caso de Facebook o Twitter, semanales en Instagram y en la plataforma YouTube, dependiendo del contenido disponible, aunque realizan múltiples subidas de vídeos todas las semanas.

Manos Unidas se incluye en el catálogo de organizaciones que, dentro de la Agencia Española de Cooperación Internacional para el Desarrollo, aúna a más de un centenar de ONGs, entre las que podemos destacar:

- Acción contra el hambre

- ACSUR: centrada sobre todo en Derechos Humanos

- ANESVAD: se centra en salud y enfermedades tropicales, fundamentalmente lepra, úlcera de Buruli y pian.

- Ayuda en Acción: pobreza y desigualdad como intereses centrales.

- Cáritas: más global, desarrolla campañas de temática mucho más variada.

- UNICEF: centrada sobre todo en niños y salud, protección y educación.

- FAD: temas de drogadicción, con campañas centradas en la prevención en niños, menores y jóvenes.

Todas estas entidades utilizan en ocasiones a menores como protagonistas de sus campañas, dependiendo de las temáticas o las campañas presentadas, sin embargo, hemos decidido centrarnos en Manos Unidas de manera concreta por ser una de las pioneras en España, si bien es cierto que Cáritas e Intermón iniciaron su andadura unos años antes, y por ser una de las más consolidadas en cuanto a reconocimiento y trabajo. 
Dejamos para posteriores trabajos una comparación con la publicidad social de otras organizaciones pues el objetivo de este trabajo no era tanto comparar los trabajos de estas organizaciones en cuanto a sus construcciones comunicativas, sino intentar indagar y corroborar una hipótesis o tendencia comunicativa que nos parece bastante generalizada en este sector en un caso concreto.

\section{Objetivos e hipótesis}

El objetivo de este artículo es analizar la presencia de los menores en los spots de Manos Unidas, para ello se decidió optar por el visionado de las piezas de esta ONG en la plataforma Youtube, que en el título incluyan la palabra spoty que tienen las características para definirse como tales.

Trabajamos con dos hipótesis: la primera (H1) se apoya en el análisis audiovisual de las piezas y defiende la presencia mayoritaria de menores en la construcción comunicativa de las campañas de esta ONG, ya sea una presencia solo de niños o acompañados de adultos, incluye el análisis de las situaciones que se suelen presentar en las propuestas y si la presencia más feliz o más triste tiene que ver con el tipo de campaña: captación de fondos, aumento de voluntarios o dar a conocer los logros. La segunda (H2) plantea que la presencia de menores favorece o lleva a una mayor sensibilización y respaldo de la población en general hacia este tipo de entidades que se beneficia de su presencia, tanto para la captación de fondos como para el aumento en el número de voluntarios, tendencia sobre la que preguntamos a través de una encuesta con la intención de obtener información sobre este tema por parte de la sociedad.

La acotación temporal incluye todos los videos desde el año 1995 (año del primer spot disponible en la plataforma Youtube y cuyo visionado se desarrolló de manera continuada a través de la propia web de la ONG) hasta la actualidad. Hay años que no aparecen pues los requisitos establecidos no se cumplen, como es el caso del 2016. Sobre el contenido elegimos aquellos con una temática común en los países en vías de desarrollo y desechamos las campañas del Día de África, Ecuador, Kenia o La India, o las del terremoto de Haití por tener una temática ya específica que se escapaba a nuestros intereses.

Se seleccionaron 26 spots: los niños protagonizan 7 y coprotagonizan 10. En nueve no tienen presencia y no aparecen en la tabla, donde añadimos algún dato técnico a mayores:

Tabla 1: Análisis spots. Fuente: elaboración propia

\begin{tabular}{|c|c|c|c|c|c|}
\hline Campaña & Año & Duración & Tema & Mensaje & $\begin{array}{c}\text { El papel del } \\
\text { menor }\end{array}$ \\
\hline Dar y recibir & 2015 & $1 \mathrm{~m} 30 \mathrm{~s}$ & Colaboración & $\begin{array}{c}\text { Es momento } \\
\text { de ayudar a los } \\
\text { menos } \\
\text { favorecidos }\end{array}$ & Coprotagonistas \\
\hline $\begin{array}{c}\text { Lucha contra } \\
\text { la pobreza } \\
\text { ¿Te apuntas? }\end{array}$ & 2015 & $0: 30 \mathrm{~s}$ & Pobreza & $\begin{array}{c}\text { Manos Unidas } \\
\text { lucha contra la } \\
\text { pobreza }\end{array}$ & Protagonistas \\
\hline $\begin{array}{c}\text { Un mundo } \\
\text { nuevo, }\end{array}$ & 2014 & $0: 30 \mathrm{~s}$ & Colaboración & $\begin{array}{c}\text { Con la } \\
\text { pequeña }\end{array}$ & Coprotagonistas \\
\hline
\end{tabular}




\begin{tabular}{|c|c|c|c|c|c|}
\hline $\begin{array}{l}\text { proyecto } \\
\text { común }\end{array}$ & & & & $\begin{array}{l}\text { aportación de } \\
\text { cada uno se } \\
\text { puede cambiar } \\
\text { el mundo }\end{array}$ & \\
\hline $\begin{array}{c}\text { No hay } \\
\text { justicia sin } \\
\text { igualdad }\end{array}$ & 2013 & $0: 30 \mathrm{~s}$ & Desigualdad & $\begin{array}{c}\text { La mujeres } \\
\text { llevan muchos } \\
\text { años luchando } \\
\text { por tener los } \\
\text { mismos } \\
\text { derechos que } \\
\text { los hombres }\end{array}$ & Coprotagonistas \\
\hline $\begin{array}{l}\text { La salud, } \\
\text { derecho de } \\
\text { todos }\end{array}$ & 2012 & $0: 30 s$ & Colaboración & $\begin{array}{l}\text { Tu llamada } \\
\text { puede salvar } \\
\text { muchas vidas }\end{array}$ & Coprotagonistas \\
\hline $\begin{array}{c}\text { Su mañana } \\
\text { es hoy }\end{array}$ & 2011 & $0: 30 \mathrm{~s}$ & Niños & $\begin{array}{l}\text { Muchos niños } \\
\text { mueren por } \\
\text { culpa de la } \\
\text { pobreza }\end{array}$ & Protagonistas \\
\hline $\begin{array}{c}\text { Contra el } \\
\text { hambre, } \\
\text { defiende la } \\
\text { Tierra }\end{array}$ & 2010 & $0: 30 \mathrm{~s}$ & Cambio climático & $\begin{array}{l}\text { Las catástrofes } \\
\text { son una } \\
\text { llamada de } \\
\text { atención de la } \\
\text { Tierra }\end{array}$ & Coprotagonistas \\
\hline $\begin{array}{c}50 \\
\text { Aniversario }\end{array}$ & 2009 & $0: 30 \mathrm{~s}$ & Colaboración & $\begin{array}{l}\text { Llama a Manos } \\
\text { Unidas para } \\
\text { que otros } \\
\text { tengan comida }\end{array}$ & Protagonistas \\
\hline $\begin{array}{c}\text { Sabes leer, } \\
\text { ellos no. } \\
\text { Podemos } \\
\text { cambiarlo }\end{array}$ & $2007 / 2008$ & $0: 29 s$ & Educación & $\begin{array}{l}\text { La educación } \\
\text { es el futuro } \\
\text { para los niños }\end{array}$ & Protagonistas \\
\hline $\begin{array}{l}\text { Otro mundo } \\
\text { es posible, } \\
\text { depende de ti }\end{array}$ & 2006 & $0: 30 \mathrm{~s}$ & Colaboración & $\begin{array}{l}\text { Con tu ayuda, } \\
\text { se pueden } \\
\text { frenar muchas } \\
\text { cosas }\end{array}$ & Protagonistas \\
\hline $\begin{array}{l}\text { Si quieres la } \\
\text { paz, rechaza } \\
\text { la violencia }\end{array}$ & 2002 & $0: 30 \mathrm{~s}$ & Niños soldados & $\begin{array}{l}\text { Manos Unidas } \\
\text { trabaja para } \\
\text { reinsertar a } \\
\text { niños }\end{array}$ & Protagonistas \\
\hline
\end{tabular}




\begin{tabular}{|c|c|c|c|c|c|}
\hline & & & & $\begin{array}{c}\text { reclutados para } \\
\text { la guerra }\end{array}$ & \\
\hline $\begin{array}{c}\text { Si quieres la } \\
\text { paz, defiende } \\
\text { la justicia }\end{array}$ & 2001 & $0: 25 s$ & Guerra & $\begin{array}{c}\text { Ayuda antes de } \\
\text { que sea } \\
\text { demasiado } \\
\text { tarde }\end{array}$ & Coprotagonistas \\
\hline Esclavos & 1999 & $0: 30 \mathrm{~s}$ & Esclavitud infantil & $\begin{array}{l}\text { Muchas niños } \\
\text { acaban siendo } \\
\text { esclavos, no lo } \\
\text { permitas }\end{array}$ & Protagonistas \\
\hline $\begin{array}{c}\text { Invierte en } \\
\text { justicia, gana } \\
\text { en } \\
\text { solidaridad }\end{array}$ & 1998 & $0: 30 \mathrm{~s}$ & Colaboración & $\begin{array}{l}\text { Manos Unidas } \\
\text { puede llegar a } \\
\text { conseguir más } \\
\text { resultados } \\
\text { positivos } \\
\text { gracias a tu } \\
\text { colaboración }\end{array}$ & Coprotagonistas \\
\hline $\begin{array}{l}\text { Cambia tu } \\
\text { vida para } \\
\text { cambiar el } \\
\text { mundo }\end{array}$ & 1997 & $0: 30 \mathrm{~s}$ & Colaboración/progreso & $\begin{array}{l}\text { Cambiando la } \\
\text { forma de } \\
\text { actuar se } \\
\text { pueden } \\
\text { cambiar } \\
\text { muchas cosas }\end{array}$ & Coprotagonistas \\
\hline $\begin{array}{l}\text { Lo dicen en } \\
\text { todas las } \\
\text { lenguas: } \\
\text { colabora }\end{array}$ & 1996 & $0: 30 \mathrm{~s}$ & Colaboración & $\begin{array}{c}\text { Manos Unidas } \\
\text { ha trabajado } \\
\text { en muchos } \\
\text { países para } \\
\text { conseguir un } \\
\text { progreso }\end{array}$ & Coprotagonistas \\
\hline $\begin{array}{c}\text { Colabora con } \\
\text { Manos } \\
\text { Unidas }\end{array}$ & 1995 & $0: 20 s$ & Colaboración & $\begin{array}{c}\text { Cuál es el } \\
\text { trabajo } \\
\text { realizado por } \\
\text { Manos Unidas }\end{array}$ & Coprotagonistas \\
\hline
\end{tabular}




\section{Campañas}

Nos detenemos a continuación, más pormenorizadamente en los spots seleccionados.

"Dar y recibir"(2015)

Campaña compuesta por dos anuncios con la misma imagen pero distinta duración. En el anuncio largo son cinco los planos protagonizados por niños, en tres de ellos sin compañía de un adulto. En el anuncio corto son cuatro los planos, dos de ellos solo los menores. Los niños pertenecen a distintas razas, y no es posible definir la región más allá de establecer que son países en desarrollo. No sonríen, tienen el semblante serio y la mirada entristecida, en algún caso un atisbo de sonrisa, pero su mirada no comparte la misma acción. Se busca dar a conocer las pulseras solidarias que permiten colaborar con la ONG. Se recuerda la necesidad de compartir con los menos favorecidos. Los niños están en un primer plano, población de riesgo por la situación en la que se encuentran.

\section{Lucha contra la pobreza (2015)}

Esta campaña está formada por un único vídeo de 30 segundos. Se trata de un stop-motion que a su vez contiene pequeños fragmentos de videos en movimiento y fotografías: un niño escribiendo en una pizarra, sacando agua de un estanque o comiendo. Protagonizado casi exclusivamente por menores, solo en un fragmento encontramos un adulto con un bebé en brazos. Destaca la imagen de un niño con la cabeza sobre un alambre de espino, es una instantánea que denota tristeza y sufrimiento. Al final, dos niñas: la primera, de apenas un año, sonríe a la cámara con una expresión dulcificada; la segunda, algo mayor, intenta mostrar una sonrisa aunque su rostro denota tristeza.

El argumento es positivo, mostrando el trabajo que se desarrolla desde la ONG para poner fin o paliar los problemas que sufren los países menos favorecidos, una labor que precisa de la colaboración de los espectadores para continuar.

\section{Un mundo nuevo, proyecto común (2014)}

Anuncio de 30" compuesto por trece imágenes fijas que se van sucediendo y cuyo fondo está difuminado para dar más presencia y protagonismo a los personajes. Aparecen adultos y niños, en ambos casos se encuentran frente a la cámara sonriendo. Hay una falta de espontaneidad, se muestran instantes muy precisos en los que la acción se ha detenido para sacar la imagen deseada. De los trece planos que componen el anuncio, cuatro de ellos están protagonizados por menores, en planos cortos y primero planos, mirando a la cámara y sonriendo. Estas posiciones o gestos captados escapan mucho de la naturalidad.

Su finalidad e idea principal es la solidaridad, un grado de arena aportado por muchos hace una montaña, las grandes cosas y los grandes cambios parten, en muchas ocasiones de pequeños gestos de muchas personas y eso es lo que permite cambiar el mundo y mejorar la situación de aquellas personas que se encuentran en un proceso de desarrollo y que para conseguirlo necesitan ayuda.

\section{No hay justicia sin igualdad (2013)}

Manos Unidas crea para esta campaña dos versiones de un mismo anuncio, uno de 30 segundos dividido en trece planos y otro más corto de 20 segundos con ocho planos. 
Recoge cinco declaraciones de mujeres de diferentes razas y culturas que expresan sus sueños en contra de la desigualdad. Solo una de ellas está protagoniza por una niña, que sueña con ir al colegio. Su mirada es triste y su voz apagada aunque transmite esperanza. La niña aparece cargando un cubo, después se sienta y habla a la cámara. El mismo formato se ve en el resto de declaraciones, donde las mujeres se encuentran mirando a cámara, a pesar de hablar en idiomas diferentes, las pausas que realizan y el tono de voz hace que parezca un discurso guionizado.

El argumento gira en torno al problema de la desigualdad desde sus niveles más básicos, como la no escolarización de las niñas, que no puedan elegir con quien casarse o ser maltratadas por el hecho de no ser hombre. Manos Unidas pide la colaboración para ayudarlas.

\section{La salud, derecho de todos (2012)}

Dos anuncios que comparten imagen y mensaje, de 30 y 20 segundos, con imágenes bastante dinámicas. Ambos están divididos en 10 planos que mezclan la imagen fija de un personaje con la imagen de una radiografía con una frase escrita que, a lo largo del video, cobra sentido en forma de mensaje.

Todas las instantáneas están protagonizadas por menores en situaciones médicas reales, como la espera en una sala de un hospital, una lesión o una vacuna. Los protagonistas miran a la cámara con el rostro serio y, como a la mayoría de los niños, en una situación que no les gusta. La imagen final da vida al mensaje que quiere transmitir esta campaña, dos niñas abrazándose y sonriendo a la cámara, se sienten queridas, alguien les ayuda, ahonda en el sentimiento de sentirse querido y de ser importante para otro.

Se busca informar y persuadir, tu ayuda es la que permite el tratamiento sanitario, los niños mejoran si tú ayudas y eso ocurre porque tú llamas. La llamada de alguien que te quiere y te alegra se usa para crear ese paralelismo entre la llamada de los colaboradores que aportan donativos para que estos niños reciban su tratamiento. Es una manera de decirles que sí que hay alguien que se ocupa y preocupa por ellos.

\section{Su mañana, es hoy (2011)}

Se constituye esta campaña con dos anuncios con distinta duración, 30 y 20 segundos. La versión corta cuenta con ocho planos, la versión larga con diez.

Ambos anuncios están protagonizados exclusivamente por menores. La imagen principal es un plano detalle de los ojos de un menor que da toda la información que se precisa y luego se van sucediendo una serie de fotografías en forma de flash sobre esa imagen, protagonizadas por menores de corta edad sin supervisión ni acompañamiento de un adulto. Los niños aparecen en pésimas condiciones, un bebé llorando, unos niños sobre un charco de barro, un niño rodeado de basura o acostado sobre algún tipo de material que ejerce de colchón. Todos ellos miran a la cámara con el rostro entristecido, suplicando ayuda con la mirada. Los ojos que aparecen en la imagen principal transmiten miedo, no miran fijamente a cámara pero se abren ante lo que no les gusta y les atemoriza. Esta imagen se encuentra sobre un fondo negro para enfatizar más esta mirada y que no haya otro elemento que llame más la atención.

La persuasión es el rasgo más característico de esta campaña que llama la atención sobre una situación de extremo peligro que exige una respuesta inmediata. 
Contra el hambre, defiende la Tierra (2010)

Dos anuncios componen esta campaña, una versión larga de 30 segundos en siete planos y otra versión corta con 20 segundos y cinco planos.

Este spot presenta las consecuencias del mal uso de los recursos de la tierra, lo que provoca pobreza y miseria, como se muestran en las dos últimas imágenes, donde un niño con un rostro casi imperceptible, alimenta a otro de un plato con escasa comida. No mira a la cámara, es ajeno a lo que sucede a su alrededor, solo atiende a abrir la boca y recibir el poco sustento que poseen. A su alrededor, otros niños sentados en el suelo con apenas una camiseta encima y todo su cuerpo lleno de manchas de suciedad. La otra imagen muestra un niño de corta edad, solo ante la cámara, levanta la vista y muestra una mirada llena de tristeza, de temor.

El sonido de una llamada de teléfono, las imágenes y el texto final es suficiente para transmitir al espectador el mensaje principal, una llamada de socorro al mundo para que la ONG Manos Unidas pueda seguir desarrollando sus proyectos.

\section{0 aniversario (2009)}

Este anuncio se compone de siete planos de imágenes fijas con un efecto de transición entre ellas. Los protagonistas son niños que miran a cámara, algunos sonríen y otros se concentran en lo que comen mientras se realiza. Un grupo de ellos apelotonados en el suelo de una especie de comedor miran el objetivo con ojos tristes, sus bocas no sonríen. Las fotografías son instantes reales, no existe una actuación por parte de estos menores, las reacciones son auténticas, unos sonríen abiertamente y otros miran con escepticismo, juegan con la espontaneidad del momento.

Sabes leer, ellos no. Podemos cambiarlo (2007/2008)

Esta campaña se lleva a cabo durante dos años consecutivos y se realizaron dos spots.

En 2007, un anuncio de 30 segundos y tres planos muestra a niños y profesores en medio de una clase mientras escuchamos las teclas de marcación de un teléfono. Son imágenes fijas, en una de ellas aparecen los niños frente a la cámara, mirando fijamente, con ojos entristecidos y cansados. Finalmente, en una clase sin mesas ni sillas aparecen los niños, sentados en un suelo de cemento, sin libros ni lápices donde escribir, una pizarra y la profesora son los únicos instrumentos que tienen para aprender

En 2008 el anuncio es de 29 segundos y consta de seis planos. Los protagonistas son también niños. La acción que realiza cada uno de ellos se relaciona una palabra concreta: con la palabra aprendizaje una niña escribe en una pizarra de colegio, con la palabra oportunidad, dos niños realizan una reparación bajo la mirada de un adulto. En algunas imágenes el menor se encuentra mirando hacia la cámara, con una sonrisa, unas más pronunciadas que otras, pero sus rostros transmiten alegría. Los que no miran a cámara están tan enfrascados en la labor realizan que no prestan atención a su alrededor.

La idea principal es remarcar la importancia de la educación como la mejor herramienta para mejorar el futuro.

Otro mundo es posible, depende de ti (2006)

Este anuncio de 30 segundos se caracteriza por un montaje de un fondo que simula un código de barras y cada una de las barras es una imagen. 
Cada imagen está protagonizada por uno o varios niños, relacionándolos con distintas palabras. Con el término austeridad aparecen dos niñas vestidas con un sucio vestido que les queda grande. Con el término confianza vemos a un grupo de niños con ropas viejas que acompañan a un niño pequeño y una niña algo mayor que sonríen ampliamente a la cámara. La tercera palabra es el esfuerzo, un niño situado en medio de unas tierras labradas ayuda a los mayores con las labores del campo. La cuarta es la esperanza, una niña en medio de un río, vestida con pantalón corto sonríe frente a la cámara mientras el agua corre por su cuerpo. Por último, la dignidad, una mujer sonriendo porta en brazos a un pequeño con mirada temerosa, al fondo se encuentran mujeres de todas las edades con el traje típico indio y con rostros serios.

Se muestra a esas personas que cada día y día a día luchan por mejorar sus vidas, pero eso es posible si las personas más favorecidas ayudan, pues necesitan disponer de recursos externos para conseguir cambiar el mundo.

\section{Si quieres la paz, rechaza la violencia (2002)}

Un anuncio de 30 segundos denuncia el reclutamiento de niños soldados en Sierra Leona. Una secuencia en un mismo espacio dividido en dieciocho planos.

Los protagonistas son niños, contraponiendo su desarrollo según el lugar de nacimiento. Unos niños suben al autobús escolar para asistir a clases, dibujándose la normalidad en sus rostros. Detrás, unos adultos suben con un cartón pluma con la imagen de un niño semidesnudo que porta un arma, su rostro es serio y hay miedo en su mirada. Los primeros siguen con su mirada esos carteles, pues en algún lugar esos niños están luchando en una guerra. El plano final muestra un primer plano de la cara de este niño soldado, con mirada triste y dura, que debería agarrar un juguete y no un arma.

El sonido ambiente, los frenos del autobús, el barullo de los niños al despedirse de sus padres y subir al vehículo, sus pasos contra el suelo, es la única melodía que se puede encontrar, aportando un aspecto mucho más serio al anuncio. Una voz en off hace de narrador aportando datos y pidiendo la colaboración de los espectadores, su tono de voz es suave y carece de energía imprimiendo seriedad a la historia.

Su función es persuasiva, llamando la atención y buscando ayuda en una situación grave. Se trata de concienciar a la población sobre el reclutamiento infantil, problema con el que trabaja Manos Unidas.

\section{Si quieres la paz, defiende la justicia (2001)}

Este anuncio se realiza en un plano estático, lo que impacta a los espectadores.

Inicialmente, aparece un hombre con un micrófono, su mirada transmite terror y cansancio; en segundo plano, cinco niños caminan con normalidad por montículos de tierra y escombros, sus rostros están serios pero no transmiten nada. Un rótulo en la parte inferior empieza a contextualizar la imagen, en plena guerra en el Subsáhara, cinco años después. Cambia la visión de la situación, el hombre con rostro cansado se encuentra en mitad de una batalla, informando mientras unos niños corren solos para escapar de la guerra, caminan descalzos sobre los escombros, con ropas viejas y sucias. La imagen impacta aunque la situación denota falta de realidad.

El silencio acompaña la imagen, hace que el espectador centre la atención en el mensaje mientras los segundos pasan sobre una imagen en Pause. Al final, una voz en off relaciona el anuncio con Manos Unidas. El rótulo contextualiza a la imagen: "las injusticias de hoy son las guerras de mañana". 
La idea principal es concienciar sobre las consecuencias de determinadas decisiones. Las guerras vienen dadas, en ocasiones, por malas decisiones y quienes más las sufren son las personas menos favorecidas.

Esclavos (1999)

Esta campaña sobre menores utiliza una estética televisiva propia de programas como la 'teletienda o 'el precio justo'.

La secuencia tiene lugar en un plató de televisión donde un presentador muestra los tres productos 'estrella'. El primero de ellos es una niña que clava su mirada temerosa al suelo, sus ropas están viejas y le quedan grandes, el pelo corto aparenta suciedad, se trata de una "cargadora" que viene con un packaging con accesorios de trabajo. El precio es de 36 pesetas y capacidad para 100 cargas. El segundo es un kit de cuatro niños militares, fáciles de manejar en cualquier situación. Aparecen dentro de un plástico con unos pantalones cortos y una camiseta que le queda grande, además incluye cuatro pistolas. Los niños están asustados y miran hacia todos los lados sin saber qué es lo que pasa. Por último, una niña vendida como esclava sexual, que no se negará a nada, vestida con el traje típico de su región aparta la mirada de la cámara avergonzada e intenta taparse. Finalmente, el presentador precisa que hay miles de modelos a elegir y todos sin documentación.

Una voz en off masculina denuncia la situación desde la ONG. La música que acompaña es la típica melodía alegre y dinámica de los concursos de televisión con efectos de sonido que cesa cuando la voz en off aparece y se hace el silencio para darle mayor presencia.

Se trata de concienciar a través de los datos que ayudan a contextualizar la gravedad e importancia de una situación que sufren miles de personas que diariamente son tratados como objetos, vendidos como simple materia prima sin importar sus derechos.

\section{Invierte en justicia, gana en solidaridad (1998)}

En este spot de 30 segundos se suceden cuatro fragmentos de video en primer plano, por debajo unos rótulos describen las imágenes, el lugar y el papel de Manos Unidas en dichos lugares.

Tres imágenes están protagonizadas por adultos que realizan distintas labores, se encuentran cansados, no cesan en el trabajo para construirse una vida mejor. La cuarta imagen está protagonizada por niños: un grupo de menores sentados en pupitres mira al frente, atendiendo a otro niño que, de pie junto a la pizarra, explica algo al resto de la clase. Las imágenes no permiten apreciar los pequeños detalles como los rostros de los más pequeños. Son retratos de una realidad que los países en vías de desarrollo viven día a día.

Una voz en off masculina narra el trabajo de Manos Unidas desde hace 39 años, ayudando a hombres y mujeres de sesenta países a mejorar su situación, pidiendo la colaboración para seguir trabajando en estos proyectos. La melodía que se escucha es instrumental y añade un coro de voces masculino, recordando a algún tipo de cantico africano. La función informativa predomina en esta campaña que busca recordar los logros de la ONG, el cambio de vida de muchas personas, dándole los recursos necesarios para que ellos lo hagan posible. 
Cambia tu vida, para cambiar el mundo (1997) y Lo dicen en todas las lenguas: colabora (1996).

Las analizamos conjuntamente porque comparten imágenes y melodía, así como el mensaje en gran parte del contenido. Los anuncios tienen una duración de 30 segundos, la única diferencia es que el del año 1996 añade tres planos de mujeres pidiendo la colaboración en su lengua de origen.

La idea común es la mejora en la vida de los protagonistas gracias a Manos Unidas. El del año 1997 recuerda que las personas ayudadas son las que ayudan a cambiar, es decir, con pequeñas acciones se pueden conseguir grandes logros, solo hay que darles a las personas las herramientas necesarias. El anuncio consta de tres secuencias rodadas en África, América y Asia. La primera muestra una niña sonriente encargada de marcar el inicio de las clases, otros niños corren descalzos por la tierra, las ropas les quedan grandes, pero van felices con sus libros bajo el brazo porque acuden a la escuela. Allí, una niña sonríe mientras recibe un libro que agarra firmemente. Los niños prestan atención al profesor.

En el plano extra de la campaña, Lo dicen en todas las lenguas: colabora, una niña peinada con dos trenzas mira tímidamente a la cámara mientras recita, en su lengua, la palabra colabora. En las otras dos secuencias aparecen mujeres realizando distintas labores, sus rostros no muestran tristeza sino orgullo por lo que han conseguido, no solo para ellas sino para los que vendrán.

La melodía instrumental y la voz en off acompañan el anuncio en ambos casos, aunque el discurso cambia según la campaña que se trate, pero siempre una voz masculina es la encargada de la narración.

Colabora con Manos Unidas (1995)

Este es el primer anuncio disponible, su duración de 20 segundos y diecisiete planos.

Tres imágenes marcan la situación anterior al trabajo realizado por la ONG, caracterizadas por la austeridad y un de color rosado que da un tono de antigüedad y desolación. Se ve a un niño jugando con una rueda, vestido con pantalones y los pies descalzos sobre montañas de piedras y escombros, entre casas construidas con barro y paja, un hombre labrando la tierra bajo el sol y una mujer con el rostro serio y entristecido marcado por una herida en la mejilla. Un plano de cielo azul cambia el sentido de las imágenes, éstas se vuelven positivas: niños con ropas nuevas sentados en los pupitres de un colegio, atendiendo al profesor; la construcción de unas casas con bloques y cemento, hospitales con médicos que ayudan a los enfermos. Destaca una imagen donde dos niños, de raza negra y blanca, se encuentran abrazados con rostros serenos y felices, no conocen la palabra rechazo ni racismo, son amigos que se quieren sin importar el color de la piel. La última imagen muestra una chica mirando a cámara con un rostro tranquilo y una tímida sonrisa. Una voz en off describe el trabajo de Manos Unidas. La música es diferente en ambas partes. Al principio, solo se escucha un efecto de viento, después, una suave melodía instrumental hace su aparición para aportar ritmo al video. La idea es plasmar visualmente el cambio tan grande que ha conseguido Manos Unidas en algunos lugares, como la gente mejora sus condiciones de vida gracias a la ayuda recibida, como pasan de vivir en chabolas a tener una casa en condiciones o como los niños utilizan su tiempo en aprender en una escuela gracias a los profesores. 


\section{Análisis del comportamiento de los individuos ante este tipo de comunicación}

Para construir este apartado y conocer la opinión de los espectadores se desarrolló una encuesta con la intención de obtener información acerca del tema planteado. Dicha muestra se realizó a través de una plataforma que permite generar formularios de manera online y recoger los resultados automáticamente en una base de datos privada para el usuario. La encuesta estuvo activa durante diez días y para alcanzar el mayor número de encuestados se colocó en el perfil personal de Facebook con algunas de las especificaciones que deberían seguir como cumplimentar todas las preguntas del formulario y no repetirla en caso de ya haberla realizado. En total fueron 150 resultados los que se obtuvieron durante los días que se mantuvo activa.

El tiempo se acotó a diez días para evitar que los resultados se duplicaran. Además, en una red social como Facebook el contenido pierde importancia e impacto a medida que pasan los días y, a pesar de compartir la publicación de nuevo, el interés de los usuarios decae. En general, todas las preguntas tuvieron gran aceptación, si bien la correspondiente a la edad fue la de menor respuesta.

En cuanto a las temáticas destacamos tres bloques. En primer lugar, aquellas destinadas a identificar demográficamente a la población en cuanto a edad y sexo se refiere. El segundo bloque se centraba en cuestiones de conocimiento general de las ONGs, la publicidad de éstas y el uso de menores en su comunicación, así como su opinión y actitud con respecto a este tema. Por último, una serie de preguntas específicas sobre Manos Unidas y el trabajo que realizan para conocer de qué manera el encuestado tiene conocimiento de la labor de esta ONG en particular.

\section{Resultados}

Comenzamos por los datos sociodemográficos. Se realizaron diferentes segmentaciones con distintos rangos de edad.

El segmento con mayor número de respuestas es el comprendido entre 18 y 34 años, con un $57,3 \%$ sobre el total. Creemos que puede deberse a que es el segmento de la población que más utiliza las redes sociales actualmente y por ello tiene un mayor alcance. Le siguen las edades comprendidas entre 45 y 54 años, con un $11,3 \%$, el segmento de población que se sitúa entre los 35 y los 44 años, con un $6,7 \%$. En cuanto a las encuestas cuyo campo de edad está sin contestar, cabe destacar que el porcentaje es bastante elevado, un $20,7 \%$ sobre el total de encuestas realizadas.

En cuanto al sexo, las mujeres participaron más que los hombres, con un 76\% (114 respuestas) sobre el $24 \%$ del género masculino.

El segundo bloque estaba compuesto por nueve preguntas sobre ONGs, la publicidad y, sobre todo, el uso de menores en la comunicación de este tipo de organizaciones. Fueron preguntas tanto de reconocimiento como de opinión.

Las dos primeras buscaban situar al encuestado en la temática a tratar, sus respuestas son dicotómicas. La primera pregunta se refiere al conocimiento de las labores que desempeñan las ONG en general. Los 
resultados son muy positivos ya que el $92,7 \%$ de las personas que realizaron la encuesta (139) dicen conocer el trabajo de estas organizaciones, frente al 7,3\% que lo desconocen completamente.

La segunda pregunta se encamina a las campañas de publicidad que estas ONG realizan y el recuerdo sobre ellas. El 91,3\% (137) de los encuestados recuerda alguna campaña, el $7.3 \%$ (11) no y el 1,3\% ha decidido no contestar a esta pregunta. Aunque es una pregunta genérica nos muestra un resultado muy positivo ya que es elevado el porcentaje de personas que sí recuerdan alguna campaña, esto quiere decir que han conseguido alcanzar un posicionamiento en la mente del espectador.

Las siguientes preguntas del bloque tienen relación directa con el tema central del trabajo: la utilización de menores en las campañas de comunicación solidaria. Con ellas se conocerá la opinión del público y cómo reaccionan ante este tipo de publicidad.

Gráfico 1: ¿Qué opina de aquella publicidad de las ONG protagonizadas por menores? Fuente: elaboración propia.

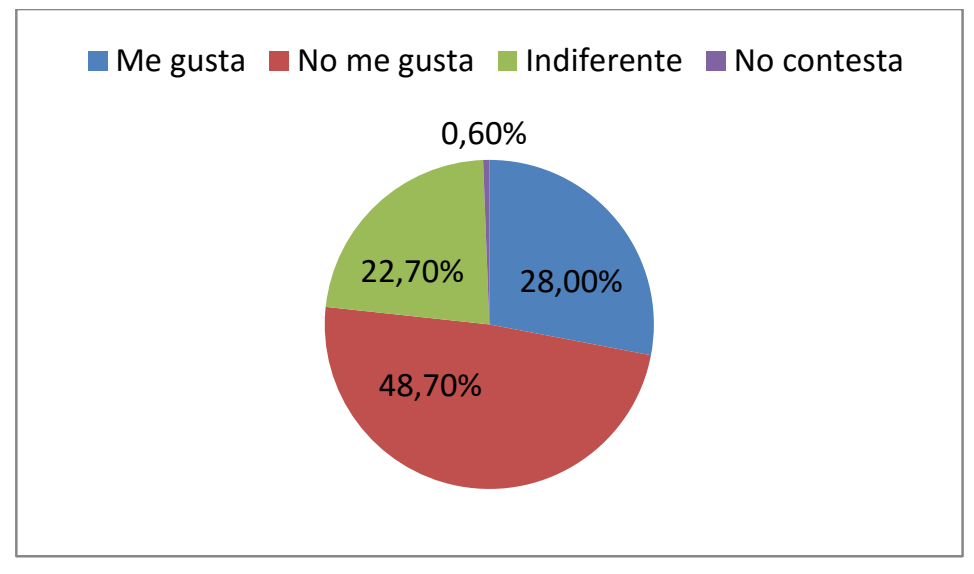

El Gráfico 1 muestra los resultados de las respuestas obtenidas acerca de la actitud de los encuestados hacia la publicidad protagonizada por menores. Como se puede observar casi la mitad de los encuestados no sienten aprecio por este tipo de publicidad, frente a un $28 \%$ (42 respuestas) a los que si les gusta. El dato interesante es el porcentaje de personas que sienten indiferencia, creemos que bastante elevado habida cuenta del auge de valores como la solidaridad y la cooperación en la sociedad actual.

La siguiente pregunta atiende a la opinión directa de los encuestados acerca de cuál creen que es el objetivo principal que tiene esta publicidad protagonizada por menores. En este caso, se presentaban tres opciones de respuesta y debían seleccionar una. El porcentaje más alto, con un $68,7 \%$, (103) pertenece a aquellas personas que opinan que el objetivo de esta publicidad es llamar la atención del público con la única finalidad de captar, ya sean fondos, socios o voluntarios. Por otro lado, el 29,3\% (44) piensa que mostrar la realidad es el propósito de estas campañas y, por último, el $2 \%$ considera que la utilización de menores es mera estética visual.

Al igual que se realizó una pregunta sobre el recuerdo genérico de alguna campaña solidaria, se preguntó si el encuestado recordaba algún tipo de publicidad, realizada por estas organizaciones, en la que los niños fueran protagonistas y a su vez si conseguían recordar a que ONG pertenecía la campaña. El 91,3\% (137) afirma que sí puede recordar al menos una campaña protagonizada por menores y de este porcentaje, el $64,96 \%$, es decir, 90 de las personas que responden son capaces de recordar a que ONG pertenece la 
campaña, frente a un $34,3 \%$ que no lo recuerda. Solamente un $8,7 \%$ es incapaz de recordar alguna campaña.

Al margen del recuerdo de las campañas realizadas, nos interesaba saber además la influencia que éstas pueden tener en el espectador a la hora de conseguir donaciones o aumentar el número de socios y voluntarios, es decir si es suficiente con las campañas para obtener la respuesta buscada o si, por el contrario, es necesario algo más. En este sentido se dirigía la pregunta realizada, a la que el 92,7\% de los encuestados ha respondido que no realizaría una donación a una ONG simplemente por lo que se muestra en su publicidad y que precisan de más información, mientras que para el 7,3\% de los encuestados si sería suficiente la publicidad que desarrollan para llevarles a la acción.

Las dos últimas preguntas de este bloque abordan el uso de menores en la publicidad llevado al campo de la sensibilización y las reacciones que provoca. Por un lado, el 78,7\% de los encuestados cree que existe una manipulación de las imágenes por parte de las ONG para sensibilizar a los espectadores, mientras que el $20,7 \%$ opina lo contrario. Por el otro lado, el $82,7 \%$ de las personas que realizaron la encuesta creen que si en lugar de menores se utilizaran adultos en este tipo de publicidad, no surtiría el mismo efecto, el $16 \%$ es contrario a esta idea, por lo que cree que la imagen es secundaria y lo que importa realmente es el mensaje.

El último bloque de la encuesta se relaciona con Manos Unidas, con la intención de conocer el grado de reconocimiento con el que cuenta. Un porcentaje elevado la conoce, un $74,7 \%$, lo que significa que están realizando un buen trabajo en cuanto a su diferenciación y posicionamiento en la mente de los espectadores. En todo caso, también hay un porcentaje importante que desconocen su existencia, por lo que su comunicación precisa de algunos retoques en algunos aspectos para reducir ese porcentaje de desconocimiento del $25,3 \%$.

En cuanto a las causas que asocian los encuestados en la labor de cooperación de Manos Unidas, se les expuso una lista en la que cada individuo podría seleccionar tantas opciones como creyera necesario. El resultado se muestra en el siguiente gráfico:

Gráfico 2: ¿Qué tipo de causas asocia a Manos Unidas? Fuente: Elaboración propia

\begin{tabular}{|c|c|}
\hline Pobreza infantil & $62,70 \%$ \\
\hline Violencia de género & $3,30 \%$ \\
\hline Asistencia social & $12 \%$ \\
\hline Defensa de los Derechos Humanos & $41,30 \%$ \\
\hline Pobreza & $50,70 \%$ \\
\hline Lucha contra el hambre & $54 \%$ \\
\hline Otros & $1,30 \%$ \\
\hline Sin respuesta & $7,30 \%$ \\
\hline
\end{tabular}


Como se puede observar la opción que destaca por encima de las demás es la pobreza infantil, seguido de la lucha contra el hambre (que es la verdadera causa por la que se creó la organización) y la pobreza. Esto puede ser debido a que, como se concluyó en el análisis de los spots de Manos Unidas, la gran mayoría de ellos están protagonizados o coprotagonizados por menores independientemente del tema que trata, esto puede causar confusión a la hora de relacionar la ONG con las causas por las que trabaja, aunque si es cierto que ahonda muchos temas vinculados con la infancia.

\section{Conclusiones}

Las ONG realizan acciones y campañas contra la pobreza, buscando denunciar y concienciar de este gran problema, utilizando la comunicación para transmitir los mensajes necesarios a la población para alcanzarlos de manera directa. Sin embargo, del mismo modo que la comunicación comercial debe tener un tratamiento especial a la hora de exhibir ciertas imágenes, ya que puede herir la sensibilidad de las personas, la comunicación solidaria también debe tener en cuenta dichas circunstancias.

La primera hipótesis que planteamos se centraba en la comunicación audiovisual de Manos Unidas y la utilización de los menores. Tras el análisis de las propuestas audiovisuales presentadas, establecemos las siguientes conclusiones:

La mayoría de piezas son de 30 segundos, destaca la campaña 'Dar y recibir', algo más larga, o la secuencia 'Flash', entre los 20 y 30 segundos. En algunos casos, hay una versión más adecuada a televisión y otra más corta de 20 segundos.

Con respecto a las imágenes:

- Cuando los protagonistas principales o únicos son menores, el mensaje no siempre les alude a ellos, aunque su imagen es utilizada como referencia.

- La mayor parte de la comunicación está protagonizada por menores, ya sean solos o acompañados por un adulto.

La utilización de los niños es una práctica habitual en la comunicación de Manos Unidas, ya en la Tabla 1, elaborada para el análisis general de los spots, observábamos como de los treinta y tres anuncios analizados, veinticuatro de ellos estaban protagonizados o coprotagonizados por menores.

Se utilizan muchos primeros planos que buscan enmarcar los rostros, mostrar con sus miradas lo que viven y sienten. A veces sonríen, otras veces los rostros tristes o serios son los que acompañan al personaje. Se confirma de manera mayoritaria que los niños aparecen felices en aquellas propuestas donde se manifiestan los avances obtenidos por Manos Unidas y la tristeza es más habitual es sus rostros cuando las campañas buscan aumentar la captación de fondos o socios

Las campañas que muestran cambios en un lugar por el trabajo de la ONG diferencian normalmente dos secuencias: primero con imágenes austeras, negativas, con adultos y niños trabajando en la calle o en el campo; la segunda, más positiva: niños en el colegio, personas atendidas por médicos, mujeres sonriendo. Es una manera sencilla de transmitir la complicada labor que realiza una ONG, mostrar situaciones que se asemejen a un antes y después. 
Los paisajes naturales, pueblos devastados por catástrofes, casas con escasas pertenencias o colegios construidos bajo la improvisación de materiales son los fondos elegidos para estos spots, salvo un caso que se desarrolla en un plató de televisión.

La palabra siempre la tiene un narrador externo, una voz en off que habla mientras se suceden las imágenes, solo en dos ocasiones los protagonistas ponen voz al propio anuncio. La música en la mayoría de los casos es instrumental, acompañando sin resaltar por encima de las imágenes.

Aunque la temática suele ser variada hay un eje temático que está siempre presente, y no es otro que la pobreza, ésta aparece en cualquiera de sus formas.

En el caso de la comunicación publicitaria, la presencia de niños y niñas aumentado exponencialmente en los últimos años, ya sea como protagonista o como destinatario del mensaje, en todos y cada uno de los medios de comunicación, sin excepción. La Asociación de Usuarios de la Comunicación (2000) reconoce los niños desarrollan tres tipos de roles:

- Cuando los niños son protagonistas o coprotagonistas del mensaje publicitario siendo su presencia fundamental para el desarrollo de la trama narrativa del anuncio.

- Los anuncios de menores (actúan como consumidores directos del producto).

- Los anuncios para menores (cuyo mensaje está destinado a estos niños como objetivo principal).

Podríamos afirmar que el primero de los roles señalados es el mayoritario que los menores desempeñan en la comunicación solidaria en general y, en el caso de Manos Unidas en particular. El menor, en todo caso, funciona como un buen reclamo publicitario y por ello cada vez es más demandado por las marcas, la Asociación de Usuarios de la Comunicación afirma que, aproximadamente, un tercio de los anuncios televisivos están protagonizados por uno o varios menores, independientemente del público objetivo al que vaya destinado, con la finalidad de dotar al producto o servicio de un valor añadido, las marcas lo utilizan como una simple llamada de atención y la comunicación solidaria se contagia del mismo contexto. Es decir, al igual que ocurre en la publicidad comercial, la utilización de los menores adquiere una serie de valores e interés que repercuten en la persona que lo ve y que, en este caso, favorece la acción buscada.

Se destaca además que, al igual que los anuncios protagonizados por mujeres u hombres, los protagonizados por niños, desde sus inicios, se caracterizan por la desigualdad en cuanto a los valores otorgados a unos y otros. En el caso de los varones se les atribuye una relación con la valentía o el ingenio mientras que a las niñas otras cualidades más relacionadas con la docilidad o la ternura.

En segundo lugar, la $\mathrm{H} 2$ planteaba que esta ONG, al igual que otras, se beneficia de la sensibilización innata de los individuos hacia la figura del menor, con el objetivo de captar mayor número de fondos y socios.

La encuesta desarrollada, sin más ánimo que ser una representación de una serie de opiniones, manifiesta en sus resultados que para la mayoría de los preguntados las ONGs utilizan la imagen de los niños para tocar la fibra sensible de las personas y así captar su atención y, por lo tanto, su colaboración, sin embargo, no es una práctica que guste.

Un $70 \%$ de las personas preguntadas, concretamente el $68,7 \%$, opinan que el objetivo de esta publicidad es llamar la atención del público con la única finalidad de captar, ya sean fondos, socios o voluntarios y casi la mitad de los encuestados manifiestan, en todo caso, que no les gusta este tipo de publicidad, un $48,7 \%$, lo que nos lleva a pensar que el abuso de este tipo de imágenes han perdido su eficacia en gran medida, 
más teniendo en cuenta, como decíamos en el párrafo anterior, que la mayoría de los que opinan piensa que la presencia de menores busca una cierta manipulación del espectador tocando la fibra sensible.

Con respecto a la importancia de este tipo de acciones comunicativas, el $92,7 \%$ responde que no realizaría una donación a una ONG simplemente por lo que se muestra en su publicidad, y que necesitan más información para comprometerse o participar de sus actividades. El auge de todo tipo de acciones solidarias en los últimos tiempos pero, desgraciadamente, también el conocimiento de actuaciones reprobables por parte de entidades de este tipo (cabe pensar por ejemplo en el reciente caso OXFAM), lleva a los individuos a buscar cada vez más información acerca de este tipo de entidades, cómo utiliza los fondos, el comportamiento de sus trabajadores y la veracidad de sus intenciones, por lo que las campañas de comunicación funcionan en muchos casos como una primera toma de contacto antes de documentarse y decidir la participación en sus actividades.

Relacionada con lo anterior, destacar que mayoritariamente $(78,7 \%)$ los preguntados creen que existe una manipulación de las imágenes por parte de las ONGs para sensibilizar a los espectadores, y un $82,7 \%$ cree además que, si en lugar de menores se utilizaran adultos en este tipo de publicidad, ésta no tendría el mismo efecto, cuestión sobre la que ya incidimos anteriormente, ya que el uso de menores, al igual que en la comunicación comercial, funciona como un reclamo, al ser considerada la parte más vulnerable de la sociedad.

Finalmente, y centrándonos ya concretamente en Manos Unidas, cabe destacar el alto índice de reconocimiento por parte de los encuestados de la ONG analizada, un 74,7\%, A la vista de estos resultados, podemos concluir que las campañas publicitarias llevadas a cabo por ONG son bastante recordadas por el espectador y que la 'marca', en este caso Manos Unidas, está bien ligada a la publicidad, si bien hay también que recordar la necesidad de determinados ajustes comunicativos, pues una cuarta parte de los preguntados no consiguen realizar esa relación.

Como conclusión final es preciso realizar una reflexión hacia este tipo de publicidad. La sensibilidad es algo que reside en el interior de las personas y hay muchos recursos que la pueden hacer aflorar, por lo que es necesario no abusar de este tipo de imágenes como reclamo. Como es obvio la utilización de menores no es algo que deba prohibirse, pero si acotarse, sobre todo en determinados ámbitos de comunicación y en determinados contenidos.

\section{Referencias bibliográficas}

Alvarado, C. (2005). La publicidad social: concepto, objeto y objetivos. Redes.com: revista de estudios para el desarrollo de la Comunicación. (2), 265 - $284 . \quad$ Recuperadode: file:///C:/Users/hp1/Downloads/Dialnet-LaPublicidadSocialConceptoObjetoYObjetivos3662339.pdf

Arestegui, C. (2015). El rol de la comunicación en el desarrollo y fortalecimiento del engagement social: caso ONG Minkando. (Tesis inédita de licenciatura). Pontificia Universidad Católica de Perú, Perú.

Asociación de Usuarios de la comunicación. (2000). Menores y medios de comunicación. Publicidad, $\begin{array}{llllll}\text { televisión, } & \text { Internet. } & \text { (pp. } & 8 & - & 9\end{array}$ http://www.auc.es/Paginas/download.php?type=doc\&year=2004\&file=docu23.pdf 
Coordinadora de ONG para el Desarrollo - España. (2008). Código de conducta de las ONG de desarrollo.

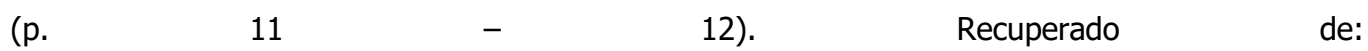
http://www.unicef.es/sites/www.unicef.es/files/recursos/Codigo de conducta 2008 CONGDE.pdf Gómez, C. (2005). Las ONG en España: de la apariencia a la realidad. Madrid: Catarata.

González, H. (2006). Estrategias de comunicación en las ONG de desarrollo. Madrid: Cideal

Gumucio-Dragón, A. (2011). Comunicación para el cambio social: clave del desarrollo participativo. Signo y pensamiento 30(58), pp. $26 \quad$ - 39. Recuperado de: http://revistas.javeriana.edu.co/index.php/signoypensamiento/article/viewFile/2454/1728

Manos Unidas. (2015). Historia y principales hitos de Manos Unidas. (pp. 1 - 4). Recuperado de: http://www.manosunidas.org/sites/default/files/web historia mu.pdf

Naciones Unidas. (2015). Objetivos de Desarrollo del Milenio: Informe 2015. (pp. 14-23). Recuperado de: http://www.un.org/es/millenniumgoals/pdf/2015/mdg-report-2015 spanish.pdf

Nos, E. (2003). Discurso publicitario y sensibilización en las ONGD: de la función social de la publicidad a la responsabilidad de la comunicación social. En Benet, J. y Nos, E. (Eds.), La publicidad en el Tercer Sector. Tendencia y perspectiva de la comunicación Solidaria. (pp. 83 - 127). Barcelona: Icaria.

Picas Contreras, J. (2001). El papel de las organizaciones no gubernamentales y la crisis del desarrollo: una crítica antropológica a las formas de cooperación. (Tesis inédita de doctorado). Universitat de Barcelona,

Barcelona. http://www.tdx.cat/bitstream/handle/10803/705/03.JPC PARTE 2.pdf?sequence $=4$ 